\title{
Ultrawide-field fundus photography of the first reported case of gyrate atrophy from Australia
}

This article was published in the following Dove Press journal:

Clinical Ophthalmology

20 August 2014

Number of times this article has been viewed

\author{
Thomas P Moloney' \\ Stephen O'Hagan' \\ Lawrence Lee Le, $^{2}$ \\ 'Department of Ophthalmology, \\ Cairns Hospital, Cairns, QLD, \\ Australia; ${ }^{2}$ City Eye Centre, Brisbane, \\ QLD, Australia; ${ }^{3}$ Associate Professor \\ of Ophthalmology, School of Medicine, \\ University of Queensland, Brisbane, \\ QLD, Australia
}

\begin{abstract}
Gyrate atrophy of the choroid and retina is a rare chorioretinal dystrophy inherited in an autosomal recessive pattern. We describe the first documented case of gyrate atrophy from Australia in a 56-year-old woman with a history of previous diagnosis of retinitis pigmentosa and worsening night vision in her right eye over several years. She was myopic and bilaterally pseudophakic, and fundus examination revealed pale optic discs and extensive peripheral chorioretinal atrophy exposing bare sclera bilaterally with only small islands of normal-appearing retina at each posterior pole. Visual field testing showed grossly constricted fields, blood testing showed hyperornithinemia, and further questioning revealed consanguinity between the patient's parents. We then used the patient's typical retinal findings of gyrate atrophy to demonstrate the potential use of ultrawide-field fundus photography and angiography in diagnosis and monitoring response in future treatment.
\end{abstract}

Keywords: gyrate atrophy, ultrawide-field retinal photography, angiography, retinal photography, hyperornithinemia

\section{Introduction}

Gyrate atrophy of the choroid and retina is a rare chorioretinal dystrophy inherited in an autosomal recessive pattern. Patients typically report night blindness and/or loss of peripheral vision, usually in the second decade of life. More than 200 individuals with gyrate atrophy have been reported since it was first described in the late 19th century, with cases mainly reported from Finland, the US, Japan, and France. ${ }^{1}$ Although there have been anecdotal reports of gyrate atrophy cases in Australia, we could not identify a case reported in the literature. Thus, to our knowledge, we report the first documented case of gyrate atrophy from Australia and document the clinical findings with ultrawide-field fundus photography and angiography.

\section{Case report}

A 56-year-old woman who reported being previously diagnosed with retinitis pigmentosa and open-angle glaucoma 20 years prior was referred for ongoing worsening night vision and peripheral vision in her right eye over several years. She reported being myopic since childhood and had used latanoprost at night into both eyes over a long period. She had a past medical history of hypertension, depression, and elevated cholesterol. On examination, best-corrected visual acuity was hand movements in the right eye and 6/12 in the left eye with refractive errors of -1.75 in each eye. Intraocular pressures were $18 \mathrm{mmHg}$ in each eye. Anterior segment examinations were quiet bilaterally. Ten years previously she had developed bilateral posterior subcapsular cataracts and was now bilaterally pseudophakic with patent posterior
Correspondence: Thomas P Moloney Department of Ophthalmology, Cairns Hospital, The Esplanade, Cairns North QLD 4870,Australia

Tel +6I 742260000

Email thomas.moloney@health.qld.gov.au 

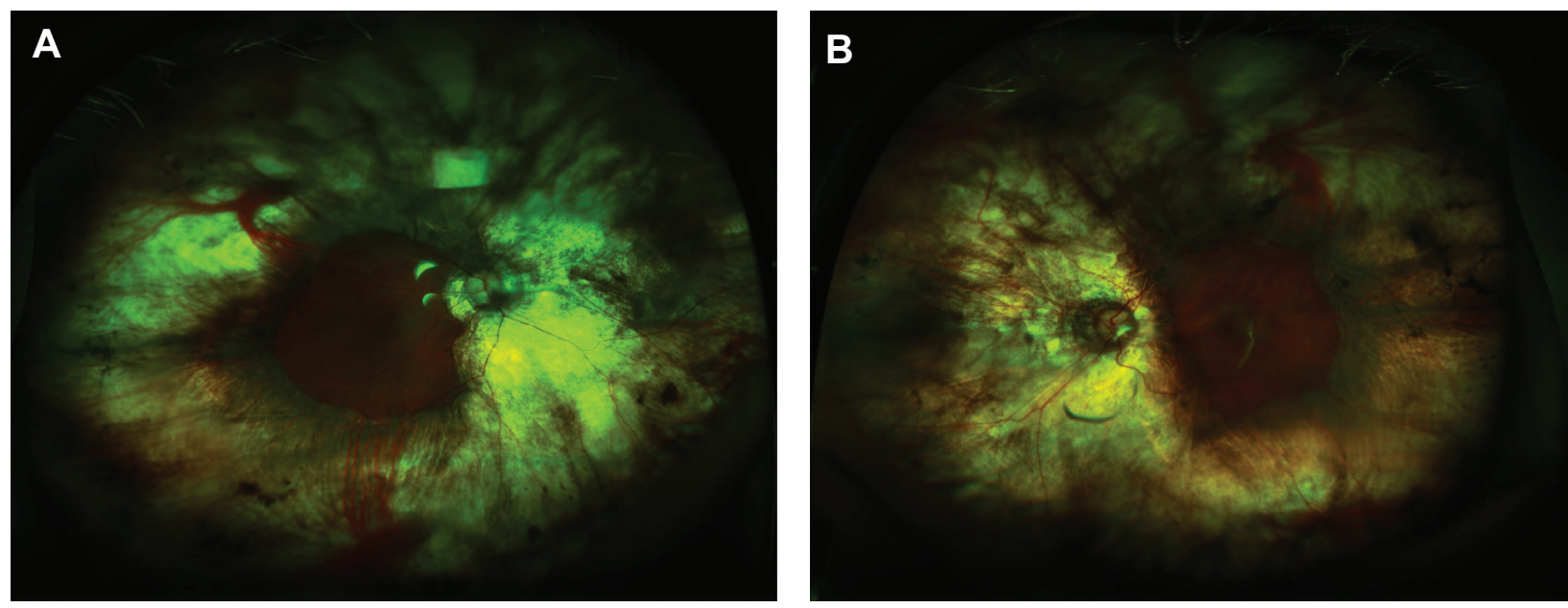

Figure I Ultrawide-field fundus photography of gyrate atrophy (Optos Imaging System). Extensive chorioretinal atrophy with remaining central macula islands at the posterior poles demarcated by pigmented borders.

Notes: (A) Right eye; (B) left eye. Optos ${ }^{\circledR}$ (Dunfermline, United Kingdom).

capsulotomies. Fundoscopy revealed pale optic discs and extensive peripheral chorioretinal atrophy exposing bare sclera bilaterally. Only small islands of retina at each posterior pole still appeared to be clinically normal (Figure 1). These islands were sharply demarcated from the atrophic areas by a pigmented border (Figure 1).

Visual field testing showed almost total constriction of the right visual field and also severe peripheral constriction of the left visual field (Figure 2). Fundal fluorescein angiography confirmed significant peripheral choroidal atrophy (Figure 3). Routine bloods tests were normal but serum ornithine was elevated at $206 \mathrm{umol} / \mathrm{L}$ (reference range
27-98 umol/L). Extensive visual electrodiagnostic testing, including electroretinography, pattern electroretinography, multifocal electroretinography, electro-oculography, visual evoked potential, average visual evoked potential, and Farnsworth-Munsell 100 (all performed to International Society for Clinical Electrophysiology of Vision standards), showed virtually abolished responses in scotopic and photopic conditions, confirming an advanced retinal dystrophy. On further questioning, the patient reported a history of consanguinity, with her parents being first cousins - thus potentiating an autosomal recessive inheritance and clinching the diagnosis of gyrate atrophy.
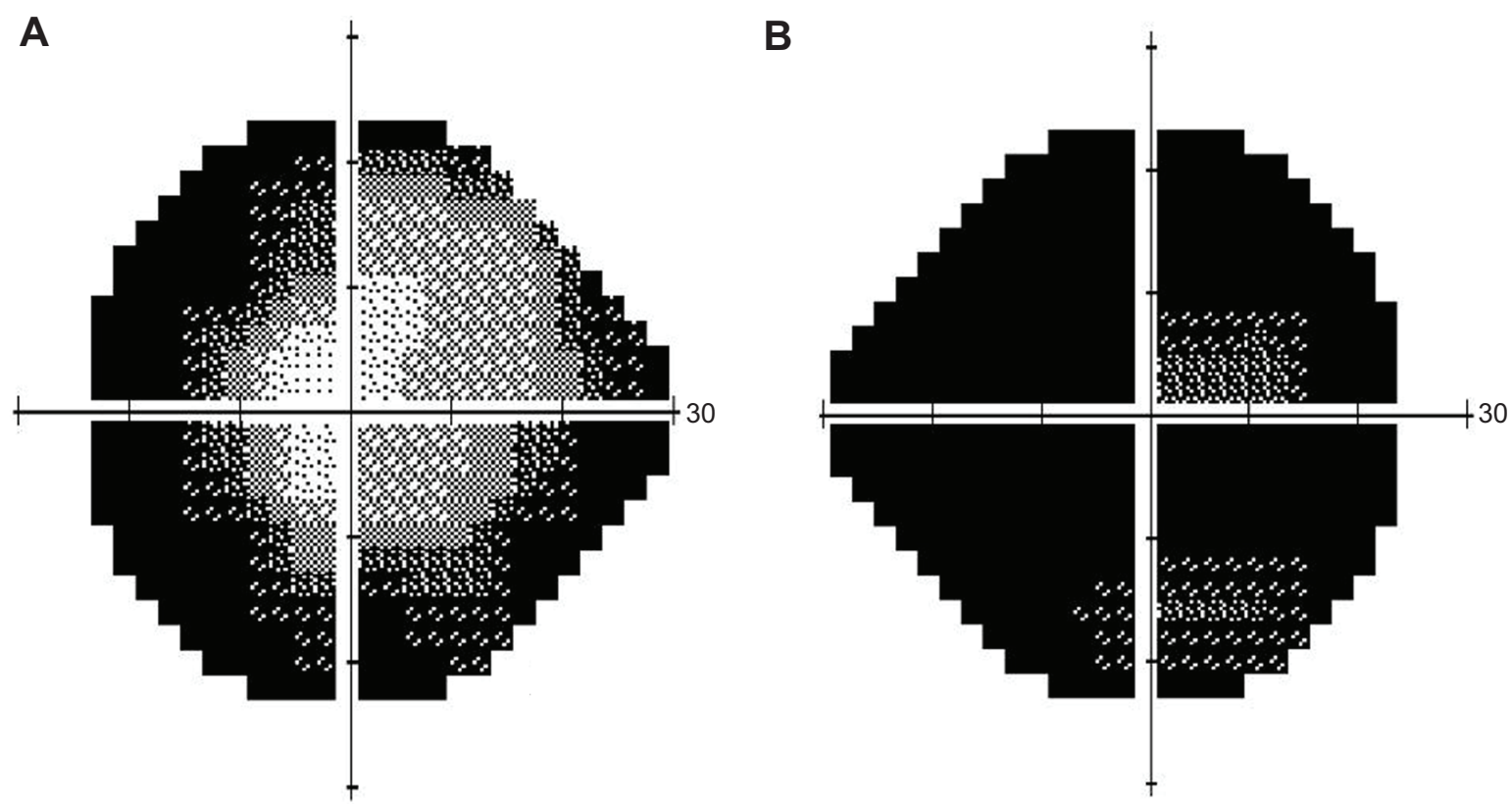

Figure 2 (A) Grayscale visual field testing of the left eye; (B) grayscale visual field testing of the right eye (Carl Zeiss Meditec AG, Jena, Germany). 

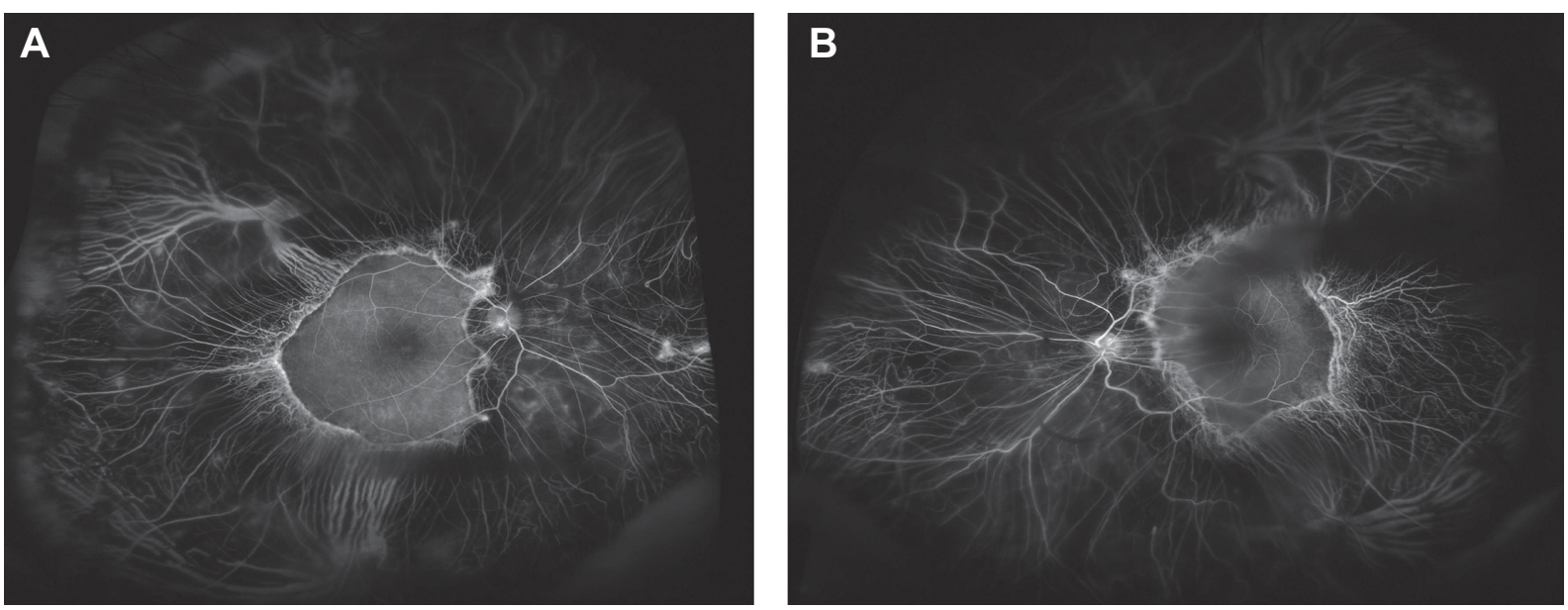

Figure 3 Ultrawide-field fluorescein angiography of gyrate atrophy (Optos Imaging System). Notes: (A) Right eye; (B) left eye. Optos ${ }^{\circledR}$ (Dunfermline, United Kingdom).

\section{Discussion}

Clinically, gyrate atrophy appears as well-circumscribed areas of atrophy of the choroidal vessels, retinal pigment epithelium, and photoreceptors in the midperipheral retina. ${ }^{2}$ Typically, scalloped atrophic areas are well demarcated from the posterior pole, which although it appears clinically normal usually also has areas of photoreceptor cell loss. ${ }^{3}$ Gyrate atrophy has been associated with serum hyperornithinemia due to a deficiency of the vitamin B6-dependent enzyme ornithine ketoacid aminotransferase (OAT), and the human OAT gene has been localized to chromosome $10 .{ }^{4}$

Our case is typical of other gyrate atrophy cases in terms of retinal findings, myopia, early cataract formation, serum hyperornithinemia, and an autosomal recessive inheritance pattern. We have commenced treating the patient with a lowarginine diet and pyridoxine (vitamin B6), and plan to follow her up with serial visual field testing, serum ornithine levels, and retinal photography/angiography. Although the efficacy of these treatments has been variable, ${ }^{5}$ we are hopeful that we will preserve the patient's remaining visual function. In the future, diseases like gyrate atrophy with known molecular and genetic foundations hopefully may become targets for enzyme replacement treatments or gene therapy.

\section{Disclosure}

The authors report no conflicts of interest in this work.

\section{References}

1. Sergouniotis PI, Davidson AE, Lenassi E, Devery SR, Moore AT, Webster AR. Retinal structure, function, and molecular pathologic features in Gyrate Atrophy. Ophthalmology. 2012;119:596-605.

2. Yuan A, Kaines A, Jain A, Reddy S, Schwartz S, Sarraf D. Ultrawidefield and autofluorescence imaging of choroidal dystrophies. Ophthalmic Surg Lasers Imaging. 2010;41:e1-e5.

3. Wilson DK, Weleber RG, Green WR. Ocular clinic-pathologic study of gyrate atrophy. Am J Ophthalmol. 1991;111:24-33.

4. O'Donnell J, Cox D, Shows T. The ornithine amino-transferase gene is on human chromosome 10. Invest Ophthalmol Vis Sci. 1985;26:128.

5. Kaiser-Kupfer MI, Caruso RC, Valle D, Reed GF. Use of an argininerestricted diet to slow progression of visual loss in patients with gyrate atrophy. Arch Ophthalmol. 2004;122:982-984.
Clinical Ophthalmology

\section{Publish your work in this journal}

Clinical Ophthalmology is an international, peer-reviewed journal covering all subspecialties within ophthalmology. Key topics include: Optometry; Visual science; Pharmacology and drug therapy in eye diseases; Basic Sciences; Primary and Secondary eye care; Patient Safety and Quality of Care Improvements. This journal is indexed on

\section{Dovepress}

PubMed Central and CAS, and is the official journal of The Society of Clinical Ophthalmology (SCO). The manuscript management system is completely online and includes a very quick and fair peer-review system, which is all easy to use. Visit http://www.dovepress.com/ testimonials.php to read real quotes from published authors. 